\title{
Research on Performance Evaluation of Diversified Government Quality Work and Analysis on Application Practice in Nei Mongol
}

\author{
Lei Feng, Juxiu Huang * and Jingxing Liao \\ China National Institute of standardization, Beijing 100191, China
}

\begin{abstract}
The evaluation of public satisfaction with government quality work is an evaluation form to evaluate government performance from the perspective of the public. The evaluation process is open and transparent, and the results are relatively objective and fair. Taking the application practice in Nei Mongol as an example, in this paper, an index framework is designed and constructed, 12 leagues and cities in the whole region are covered by the investigation, and the actual effect of local quality work is explored and analyzed in combination with big data technology so as to provide enlightenment and reference for relevant research work in the quality field.
\end{abstract}

Keywords: Quality work, Satisfaction, Application Practice.

\section{Introduction}

The social public satisfaction evaluation of government quality work is one of the effective methods to connect quality management departments and the public [1]. The public is an external evaluation subject introduced by the government departments when extending the evaluation angle to the outside on the basis of internal evaluation. On the one hand, the introduction of the external evaluation subject promotes the transparency and openness of quality performance evaluation; On the other hand, it promotes the diversification of evaluation paths and evaluation methods, providing a new idea for accelerating the gradually scientific and standardized government performance evaluation [2]. Taking the survey data of Nei Mongol government's quality work satisfaction as an example, based on the statistical survey results, in this paper, the actual effect of local quality work was explored by multidimensional research of the evaluation results such as the overall analysis, regional analysis, key area analysis, influencing factor analysis and others, providing enlightenment and reference for the research of quality work performance evaluation.

* Corresponding author: 1053038950@qq.com 


\section{Analysis on application practice in Nei Mongol}

The evaluation of social public satisfaction with the quality work of Nei Mongol government adopted Likert 5-level scaling method [3]. The evaluation content includes five major fields of product quality, engineering quality, service quality, environmental quality and quality awareness, with a total of 5 first-level indicators, 13 second-level indicators and 31 thirdlevel indicators. The evaluation covered 12 leagues and cities in the autonomous region. 3813 valid samples were collected through the questionnaire survey of residents' satisfaction. The SPSS reliability analysis, KMO value and Bart spherical test results showed that the KMO value was 0.973 , the significance was less than 0.05 , the reliability value was 0.943 , and the reliability and validity were good.

\subsection{General situation}

The Nei Mongol Autonomous Region Government scored 82.65 points in the social public satisfaction evaluation of quality work. Therein, the product quality satisfaction was the highest, with 83.83 points; the second was quality consciousness, with 82.74 points; the satisfaction scores of engineering quality, service quality and environmental quality were $82.33,82.25$ and 82.10 respectively. Please see the following figure 1 .

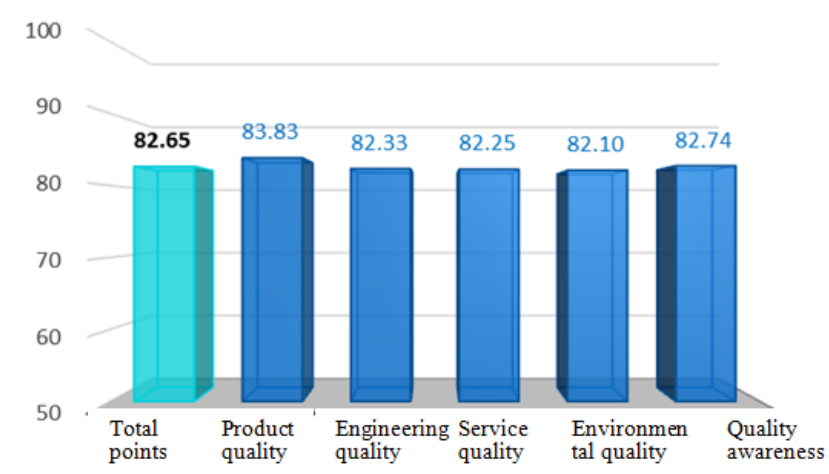

Fig. 1. Overall situation of social public satisfaction evaluation of Nei Mongol government quality work.

\subsection{Regional analysis}

The evaluation results of regional quality work satisfaction showed a trend of being "high in the middle and low in the west". The satisfaction in the central region was the highest, with 83.53 points, which was 0.88 point higher than the overall level of the autonomous region. The satisfaction in the eastern region took the second place, with 82.84 points. The western region was relatively low, with 79.8 points. Among the 12 leagues and cities, 7 leagues and cities' satisfaction were higher than the average level of the whole region, among which Tongliao, Wulanchabu, Erdos, Baotou and Hohhot were in the top 5 with scores of 83.91, $83.89,83.51,83.48$ and 83.24. The satisfaction of 5 leagues and cities was lower than the average level of the whole region, with Xilingol, Wuhai and Alxa at the bottom 3, scored $81.77,79.56$ and 77.53 respectively. The imbalance of quality development among regions still existed in the whole region, and the quality advantages in some regions were not prominent enough. Please see the figure 2. 


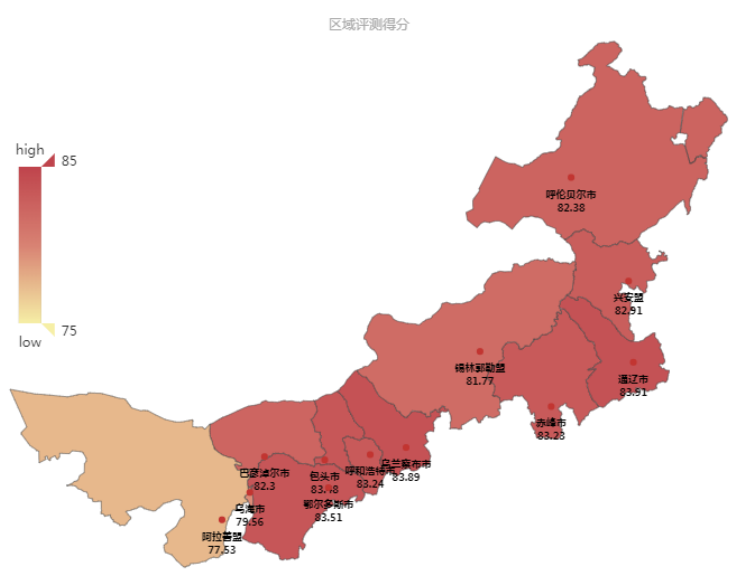

Fig.2. Regional Evaluation Results.

\subsection{Evaluation situation of key areas}

In the evaluation of product quality satisfaction, the drug quality satisfaction was higher while the special equipment quality satisfaction was lower. Judging from the monitoring indicators, the satisfaction with drug quality was the highest, with 85.10 points. The satisfaction with the quality of special equipment was relatively low, with 82.45 points. The quality satisfaction of agricultural products, household durable goods, food and daily consumer goods was 84.76 points, 84.05 points, 83.96 points and 83.12 points respectively. The main influencing factors that led to the low satisfaction evaluation score of the "special equipment quality" were analyzed as follows: $32 \%$ of the respondents thought that there was a lack of regular maintenance, $24 \%$ thought that there were potential safety hazards, and $24 \%$ thought that maintenance personnel were not in place.

In the evaluation of engineering quality satisfaction, the traffic engineering quality satisfaction was slightly higher than the constructional engineering quality satisfaction. Judging from the monitoring indicators, the satisfaction with traffic engineering quality was relatively high, with 82.70 points. While, the quality satisfaction of the constructional engineering was relatively low, with 81.97 points. Judging from the main factors that affect the evaluation of engineering quality satisfaction, the poor sound and heat insulation effect of the houses and the cracks appeared on the wall surface and floor slabs of the houses were the main reasons that affected the public's evaluation of the quality of the constructional engineering. Unreasonable design and construction, jerry-building and poor quality of main structures were the main reasons that affected the public's evaluation of traffic engineering quality [4].

In the evaluation of service quality satisfaction, the life service satisfaction was low. Judging from the monitoring indicators, the quality satisfaction of the productive services such as bank and long-distance and short-distance transportation services was high, with 83.49 points, 83.07 points and 83.01 points respectively. The satisfaction with the living services provided directly to residents, such as providing for the aged and family decoration, was relatively low, with 79.98 points and 80.7 points respectively. Among many influencing factors, insufficient nursing facilities, low quality of nursing staff and shortage of services were the main factors affecting the quality of pension services. Poor market order, poor personnel quality and lack of service supervision were the main factors affecting the quality of family decoration services. 
There was still a big gap between the evaluation results of the environmental quality satisfaction and the expectations of the public. Judging from the monitoring indicators, the public's satisfaction with the water environment quality was still at a relatively low level, with a score of 81.55 points, which was the lowest in the 13 second-level indicators. The reasons were as follows: $40 \%$ of the unsatisfied public thought that domestic waste pollution was serious, $27 \%$ of the dissatisfied public thought that the industrial emissions were too high, and $17 \%$ of the unsatisfied public thought that the agricultural pollution was serious. The satisfaction with air quality was 82.65 points, on which industrial exhaust gas, automobile exhaust gas and domestic exhaust gas pollution had a certain negative impact.

Quality publicity and information disclosure were still needed to be further strengthened in the evaluation of quality awareness satisfaction. Local residents paid high attention to quality, with 84.53 points. Residents fully affirmed the improvement of local quality work and the handling of quality complaints, while saying that quality publicity and information disclosure work are to be further strengthened. According to further investigation, $37 \%$ of the residents interviewed who were "not very satisfied" or "very unsatisfied" thought that the disclosure of quality and safety information was not timely or accurate, $35 \%$ of the residents thought that the open and publicity channels of quality information were few, and $26 \%$ of the residents thought that the publicity activities were few and small in scale.

\subsection{Analysis of influencing factors}

According to the monitoring results, the satisfaction of different gender respondents with government quality work varied slightly, and the scores were tended to be consistent, with men scoring 82.81 points and women scoring 82.43 points. From the point of age, the youth group showed the highest satisfaction with the government's quality work, with 82.95 points. The middle-aged group took the second place, with 81.18 points. The satisfaction of the elderly group was relatively low, with 79.48 points. From the perspective of academic qualifications, the respondents with high academic qualifications were more satisfied with the quality work of the government. Among them, the respondents with bachelor's degrees showed the highest satisfaction of 83.47 points, while the satisfaction degree of the respondents with primary school qualification or below was 79.65 points. Judging from different household registration types and income situations, the satisfaction with the government quality work of the rural respondents was lower than that of the urban respondents [5]. Among the respondents who revealed the average monthly income of their families, the satisfaction with the quality work increased with the increase of their income, with the highest satisfaction degree of 84.71 points from the respondents whose average monthly income of urban families was RMB 10001-20000 yuan.

\section{Conclusion}

Based on the actual measurement and analysis of Nei Mongol government quality work satisfaction through the diversified government quality work performance evaluation research, and combined with the measurement results, the following suggestions are put forward for Nei Mongol to carry out quality improvement actions, strengthen overall quality supervision, comprehensively improve quality level, and promote the implementation of the construction of province of high quality. 


\subsection{Focusing on the quality needs of the public so as to benefit people's livelihood by taking well-targeted steps}

Safeguarding and improving people's livelihood is the fundamental task of social construction, and the fundamental way to improve the satisfaction evaluation results of government quality work. First of all, in order to make up for the shortage of people's livelihood development, governments at all levels in Nei Mongol Autonomous Region should focus on the "demands" and "concerns" of the masses in product quality, engineering quality, service quality and environmental quality, and strengthen the supervision of pension services, family decoration services, tourism services, water environment quality and other fields. Secondly, governments should strengthen quality social supervision and public opinion supervision, establish and improve the feedback mechanism of quality information transmission, strengthen comprehensive quality management, protect people's quality rights and interests, and enhance residents' senses of acquisition and happiness.

\subsection{Learning from the preponderant experience of quality to promote coordinated regional development}

Facing the current situation of unbalanced quality construction level in various leagues and cities, we should thoroughly implement all-round development and balanced development, and give full play to the preponderant experience of high-level regions in quality construction through the endogenous power development mode of economic development to drive the quality construction development in backward regions. ${ }^{6}$ Adhering to carry forward the advantages and characteristics of various regions, we should, through exchanges, experience and resource sharing and other ways and means, achieve the quality improvement work of "making the advanced better, driving the development of backward by the advanced and realizing mutual development", improve the public's satisfaction with the quality work, and effectively achieve the coordinated development of regional quality work to enable the whole people to share the results of quality development.

\subsection{Consolidating quality infrastructure and promoting high-quality development}

The quality foundation is an important guarantee to carry out quality improvement actions and to promote high-quality development. ${ }^{7}$ The evaluation results showed that the quality development of products, engineering, services and other fields in the whole region still lagged behind the needs of economic and social development and the people's needs for a better life, which is related to the low level of quality infrastructure development. It is suggested to further strengthen the construction of quality infrastructure in the whole region. According to the regional characteristics and the advantages of traditional industries, we should promote the "internet plus NQI quality model", strengthen the technology chain design and integrated application of "measurement + standards + inspection and testing + certification and accreditation" technology, strengthen the overall integration and construction of quality infrastructure, and effectively improve the quality foundation support capacity so as to serve the high-quality development of the economy. ${ }^{8}$

\section{Acknowledgements}

This paper is funded by the Government Quality Monitoring, Evaluation and Assessment System Improvement and Implementation Project (582019C-7110) and the Quality Infrastructure Collaborative Service Application Research Project (582019C-6930). 


\section{References}

1. M L Morris, R Tripp, and A A Dankyi. Adoption and Impacts of Improved Maize Production Technology: A Case Study of the Ghana Grains Development Project, International Maize and Wheat Improvement Center (CIMMYT) (1999)

2. J O Ouma, F M Murithi, W Mwangi, H Verkuijl, M Gethi, and H D Groote. Adoption of Maize Seed and Fertilizer Technologies in Embu District, Kenya, International Maize and Wheat Improvement Center (CIMMYT) (2002)

3. X G Luo and H Y Zhang, Y Hong. Evaluation dimension analysis of government service quality SERVQUAL [J]. Administrative Forum, 3,35-37 (2008)

4. G F Cui. On the Development of Government Service Quality Management [J]. Hubei Social Sciences, 8,37-38(2005)

5. W B Li and L H Lai, Government Performance Satisfaction and Residents' Well-being: An Empirical Study in Guangdong Province [J]. China Administration, 8,53-57(2013) 